\title{
Perfectionism and the Imposter Phenomenon
}

\author{
W. Lee Grubb, III \\ East Carolina University \\ Leah K. Grubb \\ East Carolina University \\ University of North Carolina at Greensboro
}

\begin{abstract}
In search of antecedents of the imposter phenomenon, this paper examines whether perceptions of an ethical climate change how an individual's concern over mistakes and personal standards relate to the impostor phenomenon. Concern over mistakes, when taken to extremes, can result in dysfunctional interactions with others. We propose that an individual's perception of the ethical climate is likely to influence how concern over mistakes and personal standards influence the impostor phenomenon. The results, based on over 600 students, reveal that both ethical climate and the two facets of perfectionism are linked to the imposter phenomenon. Notably, when there is a strong ethical climate, there becomes an increased positive relationship between concern over mistakes and the imposter phenomenon. Similarly, in the presence of a strong ethical climate, there is an increased positive relationship between personal standards and the imposter phenomenon. Practical implications suggest that the ethical climate of colleges of business may influence students' thoughts of being an imposter and contribute to future maladaptive beliefs.
\end{abstract}

Keywords: imposter phenomenon, ethical climate, perfectionism

\section{INTRODUCTION}

In spite of career or academic achievements, some individuals struggle to internalize success; they attribute their success to luck rather than skill or ability. Consequently, feelings of being a fake or fraud occur and lead these individuals to believe that at some point others will find out they are not capable of the success attributed to them. Such characteristics are otherwise known as the impostor phenomenon (IP) (Clance \& Imes, 1978). Feeling like a fake can be a pervasive problem and have lasting effects on individual well-being. The effects on people's health are clear as studies have found a link between the impostor phenomenon and feelings of depression (McGregor, Gee, \& Posey, 2008), overall mental health (Sonnak \& Towell, 2001), emotional exhaustion, and work-family conflict (Crawford, Shanine, Whitman, \& Kacmar, 2015). Roughly 70\% of individuals will experience the impostor phenomenon at some point in their life (Gravois, 2007). Despite the prevalence of the impostor phenomenon, fundamental questions remain regarding its antecedents. Impostor phenomenon antecedents are important to examine for several reasons. First, evidence indicates that the imposter phenomenon is a trait-characteristic that can occur for a variety of reasons (Clance \& Imes, 1978). Second, the impostor phenomenon occurs across gender, race, 
culture, and professions (Crawford et al., 2015). Identifying antecedents is likely to inform theory (e.g., trait-activation theory, Tett \& Burnett, 2003) and practice (McDowell, Grubb, \& Geho, 2015; Hutchins \& Rainbolt, 2017).

Those who experience IP do not have unrealistic goals, they simply do not attribute their achievements to skill or ability, but rather to luck or something else. Consequently, individuals who do set unrealistic goals, or believe that they have never achieved their difficult goals, are likely to experience perfectionism. We employ perfectionism as our personality variable to examine what gives rise to the impostor phenomenon among undergraduates. Perfectionism is a personality trait with both positive and negative connotations (Frost, Marten, Lahart, \& Rosenblate, 1990). Previous research has linked perfectionism with anxiety, stress, and depression (Bieling, Israeli, \& Anthony, 2004). More importantly, extant research finds a positive relationship between perfectionism and the impostor phenomenon (Dudau, 2014; Henning, Ey, $\&$ Shaw, 1998). However, as the impostor phenomenon is associated with a wide range of personality traits, we propose that another factor is at play in addition to perfectionism, namely the environment. We utilize perceptions of the environment to examine how perfectionism relates to the impostor phenomenon. Specifically, we test whether perceptions of an ethical climate change how an individual's concern over mistakes and personal standards relate to the impostor phenomenon. Concern over mistakes is a maladaptive dimension of perfectionism. This means that, when taken to extremes, concern over mistakes can result in dysfunctional interaction with others at home, school, or work (Frost et al., 1990). Perfectionism also has an adaptive dimension, personal standards, which refers to an individual's desire to establish and meet goals for personal satisfaction. We propose that an individual's perception of the ethical climate is likely to influence how perfectionism influences the impostor phenomenon.

We used undergraduate and graduate students in this study because the college environment is a setting where individuals are likely to experience feelings of being a fraud or fake while also striving to be perfect (Henning et al.,1998). In addition to scholastic requirements and goals, college students are likely to be influenced by their peers and the collective environment regarding what is perfect and what constitutes ethical and unethical behavior. To that end, we develop and test our hypotheses with 634 students. Our results are consistent with our hypotheses and are used to offer theoretical and practical implications.

\section{PERFECTIONISM \& THE IMPOSTOR PHENOMENON}

\section{Impostor Phenomenon}

The impostor phenomenon was first described by Dr. Pauline Clance from her observations in a clinical setting (Clance \& Imes, 1978). Individuals with the impostor phenomenon experience intense feelings that their achievements are undeserved and worry that they are likely to be exposed as a fraud (Sakulku \& Alexander, 2011). Initially, the impostor phenomenon was believed to only affect professional women (Clance \& Imes, 1978). However, feeling like an impostor is more widely experienced. For example, it has been observed to affect both genders (Bussotti, 1990), and to occur in people with different occupations such as college students (Langford, 1990), academics (Topping, 1983), medical students (Henning et al., 1998), marketing managers (Fried-Buchalter, 1992), and physician assistant students (Mattie, Gietzen, Davis, \& Prata, 2008). Regarding cultures in different countries, Caselman (2003), Chae, Peidmont, Estadt, and Wicks (1995) and September, McCarrey, Baranowsky, Parent and Schindler (2001) found that impostor feelings occurred across different cultures in Japan, South Korea, and Canada. Although the impostor phenomenon is experienced across genders, ages races, and cultures, there are some factors that are more prominently linked to the imposter phenomenon.

A number of studies have examined how personality correlates with the impostor phenomenon. Both trait anxiety (Topping, 1983) and neuroticism (Casselman, 1991; Chae et al., 1995) were found to have strong relationships with the impostor phenomenon. Several other studies have examined the perfectionism and impostor phenomenon relationship (Cusack, Hughes \& Nuhu, 2013; Dudau, 2014; Henning et al., 1998). The earliest work on perfectionism defined it as "the practice of demanding of oneself or others a higher quality of performance than is required by the situation" (Hollender, 1965, p. 94). [The perfectionist] "is constantly on the alert for what is wrong and seldom focuses on what is right" (p. 95). Perfectionism is 
commonly conceived of as a personality style characterized by striving for flawlessness and the setting of excessively high standards for performance accompanied by tendencies for overly critical evaluations of one's behavior (Stoeber \& Otto, 2006). Similar to other personality traits, perfectionism has its onset in childhood and can last throughout adult life (Flett, Hewitt, Oliver, \& Macdonald, 2002). Additionally, research finds that social media use has increased the occurrence of perfectionism among adults, with the undergraduate student demographic seeing the highest spike (Perloff, 2014; Rosen, Whaling, Rab, Carrier, \& Cheever, 2013; Grammas \& Schwartz, 2009). Research finds that impostor fears are moderately associated with perfectionistic thoughts about avoiding imperfection (Ferrari \& Thompson, 2006). These results mean impostors had the need to appear to be capable, competent, and successful in order to gain respect and admiration from others. They also strived to conceal their imperfections by not engaging in situations when they were likely to reveal their personal limitations to others. The characteristics found in impostors were similar to those found in perfectionists, who are highly self-conscious and have a strong desire to conceal their mistakes from others in order to appear perfect (Frost, Turcotte, Heimberg, Mattia, Holt, \& Hope, 1995).

The relationships between characteristics of impostors and elements of perfectionism have been supported by empirical studies. Thompson, Davis, and Davidson (1998) found perfectionistic cognitions in subjects reporting elevated levels of impostor fears, such as a tendency to externalize success, holding high standards for self-evaluation, overgeneralization of a single failure experience to their overall self-concept, and a high level of self-criticism. Thompson, Foreman, and Martin (2000) compared impostors to nonimpostors in their affective and cognitive reactions to making mistakes; they found that impostors reported a higher concern about their mistakes and a greater tendency to overestimate the number of mistakes they had made than non-impostors. In addition, impostors also reported greater dissatisfaction with their performance and viewed their performance as less successful than non-impostors. These findings provided empirical support for the observations of Clance (1985) that impostors reject any performance that does not reach their perfect standards and consider their performance as disappointing (Sakulku \& Alexander, 2011).

One difference between impostors and perfectionists is that perfectionists will not disclose their mistakes to other people because they fear being viewed as imperfect (Frost et al., 1995), while impostors will openly communicate their self-perception of imperfect performance to others (Ferrari \& Thompson, 2006). Impostors do not want to appear imperfect and actively attempt to conceal their imperfection, but paradoxically impostors do openly disclose their imperfections. A study by Cromwell, Brown, SanchezHuceles, and Adair (1990) found that impostors are different from non-impostors in that impostors feel they need to achieve perfection in order to gain others' approval. This suggests that there may be social components contributing to perfectionism in impostors. Impostors fear being exposed to others as fraudulent and lacking in ability which would cause them to attract negative judgments from others. Thompson et al. (2000) found that impostors have a higher level of fear of negative evaluation than nonimpostors, and the motive behind their achievement behavior is to meet their perception of other people's standards. These perceived social expectations may be a source of perfectionism in impostors, which could be identified as socially prescribed perfectionism.

\section{DOES PERFECTIONISM INCREASE IMPOSTOR PHENOMENON?}

Perfectionism is a trait that is believed to have a marked impact on the development and maintenance of impostor fears. Kets de Vries (2005) asserted that perfectionism is the underlying cause of neurotic imposture. Impostors set "excessively high, unrealistic goals and then experience self-defeating thoughts and behaviors when they can't reach those goals" (Kets de Vries, 2005, p. 112). Within the clinical literature on the impostor phenomenon, perfectionism is repeatedly discussed as a dominant theme, with impostors setting extremely high and often unrealistic standards for their self-evaluation (Imes \& Clance, 1984). The need to be the best, the need to be able to do everything flawlessly, and their tendency to overwork are the characteristics of impostors that are consistent with the pursuit of perfection. Impostors' tendency to

discount positive feedback and maintain high standards for self-evaluation, while being critical of their inability to realize these standards, could also be considered consistent with perfectionism (Sakulku \& 
Alexander, 2011). The present study employs two dimensions of perfectionism, concern over mistakes ("CoM") and personal standards ("PS"), in order to examine how the maladaptive spectrum of perfectionism compares to the adaptive spectrum of perfectionism.

\section{Concern Over Mistakes}

CoM may be the result of self-punishing and unattainable standards that reflect an inadequate sense of self and may lead to unyielding self-criticism and an inability to experience pleasure through normal accomplishments (Blatt, 2004). Individuals high in CoM are obsessively concerned about making mistakes, and their inherent self-doubt corrodes their ability to make decisions and act (Frost et al., 1990). CoM has been shown consistently to have a significant role in the formation and maintenance of psychological difficulties (Hewitt \& Flett, 2002). Moreover, numerous studies have found that CoM is associated with various forms of psychopathology and mental health concerns, including depression, anxiety, phobias, panic disorders, eating disorders, obsessive-compulsive disorder, somatic complaints, and suicidal ideation (Shafran \& Mansell, 2001; Lasota \& Kearney, 2017; Smith, Saklofske, Yan, \& Sherry, 2017). For nearly 60 years, scholars have believed that perfectionism has a positive relationship with psychological strain (Hollender, 1965).

The fundamental characteristics of CoM suggest that individuals with this personality trait may evaluate school situations differently from those who do not possess the trait. For example, individuals with CoM tendencies are likely to become emotionally drained, distance themselves from school, or feel they will not be able to achieve prior levels of performance which may affect subsequent school outcomes. In addition, CoM likely has similarities with socially prescribed perfectionism (Henning et al., 1998) which has been positively associated with the impostor phenomenon. Similar concerns with socially prescribed perfectionism revolve around others' expectations for one to be perfect. Similarly, CoM, in part, deals with concern over others' reactions to one's mistakes. Therefore, we hypothesize a positive relationship between $\mathrm{CoM}$ and the impostor phenomenon.

Hypothesis 1. Controlling for individual differences known to affect impostor phenomenon (e.g., race, sex), student concern over mistakes will be positively related to impostor phenomenon.

\section{Personal Standards}

Extant research finds relational strength differences between the various facets of perfectionism and the imposter phenomenon. Henning et al. (1998), reported a stronger relationship between socially prescribed perfectionism and the imposter phenomenon than with self-oriented perfectionism and the imposter phenomenon. Personal standards are similar to self-oriented perfectionism in that they both pertain to one's individual perspective and desire to be perfect. In their 1998 study of professional students in the medical field, Henning et al. (1998) reported significant positive relationships with their different perfectionism scales. However, while significant and positive, the self-oriented relationship was consistently lower than the socially prescribed scale relationship. Therefore, we propose:

Hypothesis 2. Controlling for individual differences known to affect impostor phenomenon (e.g., race, sex), student personal standards will be positively related to impostor phenomenon.

Much of the existing research on the Impostor Phenomenon focuses on the antecedents of impostorism. Impostors generally score high on neuroticism (Bernard, Dollinger, \& Ramaniah, 2002), anxious attachment and narcissistic expectations/self-promotions (Gibson-Beverly \& Schwartz, 2008), selfcriticism (Thompson et al., 1998), perfectionism (Cromwell et al., 1990), and trait and social anxiety (Chrisman, Pieper, Clance, Holland, \& Flickaug-Hughes, 1995; Topping and Kimmel, 1985). They score low in self-esteem, self-appraisal (Chrisman et al. 1995; McElwee \& Yurak, 2007), extraversion (Ross, Stewart, Mugge, \& Fultz, 2001), and attribution to success (Topping \& Kimmel, 1985). Clearly, a relationship between internal characteristics and the imposter phenomenon has been established. 
However, just as we recognize that one's personality is a combination of both inherited and environmental characteristics, we also believe that some of the factors that are correlated with the impostor phenomenon are environmental as well. These environmental characteristics likely alter the relationship between other factors that influence the impostor phenomenon. For these reasons, we propose that other factors are present which change the perfectionism and impostor phenomenon relationship. Specifically, we propose that an ethical climate will influence the relationship between different forms of perfectionism and the imposter phenomenon.

\section{DO PERCEPTIONS OF ETHICAL CLIMATE MODERATE THE PERFECTIONISM AND IMPOSTOR PHENOMENON RELATIONSHIP?}

Ethical climate is defined as "the prevailing perceptions of typical organizational practices and procedures that have ethical content" or "those aspects of work climate that determine what constitutes ethical behavior at work" (Victor \& Cullen, 1988, p. 101). Simply put, it reflects values, practices, and procedures that exist within an organization that pertain to moral behaviors and attitudes. Climate perceptions relate to "behavior outcome expectations" (Zohar \& Luria, 2004). Similar to operant conditioning logic (Komaki, 2003; Skinner, 1969), individuals can be socialized by their climate (Kelley, 1992). In other words, an ethical climate communicates and signals to members that ethical behavior is valued and supported (Luria \& Yagil, 2008). A behavior that is valued tends to be repeated, reinforced, and exhibited more frequently (Treviño, Weaver, \& Reynolds, 2006; Vardi, 2001). In addition, when employees learn that unethical behaviors are prohibited and punished, they are more likely to refrain from such behaviors (Brown, Treviño, \& Harrison, 2005; Mayer, Kuenzi, Greenbaum, Bardes, \& Salvador, 2009). Thus, a positive ethical climate is more likely to increase desirable behaviors. Such logic can be extended to other contexts, such as education, where the values, practices, and procedures of business schools, universities, and other educational institutions reflect their ethical climate. As prior evidence suggests (Deshpande, George, \& Joseph, 2000; Fritzsche, 2000; Treviño, Butterfield, \& McCabe, 1998), since ethical climate reflects shared perceptions about what is considered ethically correct behavior (Victor \& Cullen, 1987), one can expect that the ethical climate of a business school can play a significant role in shaping its students' ethical values and behaviors (Trevino et al., 1998). Individuals learn what types of behaviors are acceptable by observing cues and information from their environment (Salancik \& Pfeffer, 1978). Moreover, individuals are not only influenced by formal standards and policies of ethical conduct but also through informal influences and social norms (Victor \& Cullen, 1988) or what is considered as acceptable behavior by others (Mayer, Kuenzi, \& Greenbaum, 2010).

The mere existence of an ethical climate may not be sufficient on its own. That is, ethical climate is a perception about what is considered important in an institution, and what is considered important may not necessarily be shared or fully embraced by its members (e.g., students). A high ethical climate is likely to intensify an individual's CoM because a high ethical climate communicates to individuals in that climate what the expected ethical practices and procedures are and their importance. We argue that a high ethical climate will intensify CoM because an individual will then be made aware of where they fall short. Consequently, when individuals who are concerned over mistakes began to think or realize that they fall short in a particular climate, they are likely to question their own performance and success for a few reasons. While others may not be aware of dwindling or dwindled confidence, these individuals will begin to attribute their performance or success to other factors such as luck which is the hallmark of the impostor

phenomenon. For these reasons, we argue that an ethical climate moderates the perfectionism (e.g., concern over mistakes) and impostor phenomenon relationship. We formally hypothesize -

Hypothesis 3. Ethical climate will moderate the perfectionism and impostor phenomenon relationship such that when a strong positive ethical climate is present, the relationship between Concern over Mistakes and the imposter phenomenon will be strengthened. 
While we argue that an ethical climate will strengthen a maladaptive form of perfectionism and the impostor phenomenon relationship, we argue the same for an adaptive form, albeit for different reasons. Individuals led by personal standards will not only be aware of a high ethical climate but hope to adhere to those standards. The attempt to adhere to those standards will strengthen the relationship between personal standards and the impostor phenomenon. A high ethical climate is likely to be attractive to individuals who have high personal standards, but the frequency with which individuals must adhere to personal standards in an ethical climate will likely cause consternation when an individual falls short of their own personal standards. An individual's knowledge that they have fallen short of their own personal standards in a highly ethical climate is likely to have a confounding effect such that individuals will be sure about their imperfections but unsure about their ability. Stated differently, an ethical climate will strengthen the personal standards and impostor phenomenon relationship.

Hypothesis 4. Ethical climate will moderate the perfectionism and impostor phenomenon relationship such that when a strong positive ethical climate is present, the relationship between Personal Standards and the imposter phenomenon will be strengthened.

FIGURE 1 MODEL OF THE EFFECTS OF CLASSROOM MODALITY ON TEAMWORK

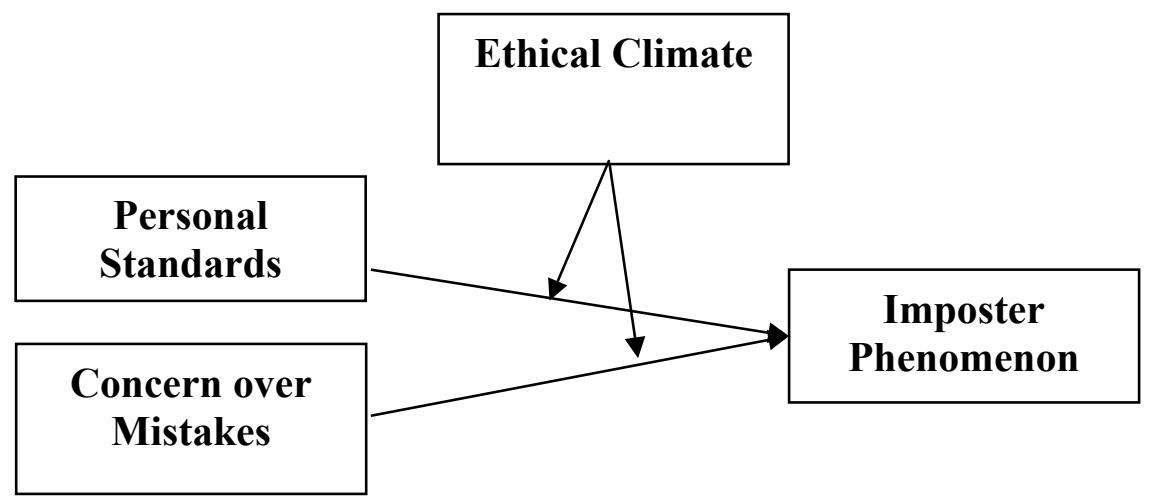

\section{METHODS}

\section{Procedure}

An instructor recruitment e-mail describing the study and the request for student participants was sent to 12 professors in a college of business at a large public university in the Southeast United States. The eemail included the verbiage for a participant recruitment email, should instructors agree to include their class(es) in the described study. The participant recruitment e-mail briefly explained the study, its voluntary nature, and the opportunity to receive extra credit in the course. The study received institutional review board approval and was carried out in a manner consistent with such approval including the use of an electronic informed consent form.

Participants were asked to complete an online questionnaire using Qualtrics. There were 782 responses. The survey included measures of participant individual differences and demographic items (i.e., year in school, etc.) and was administered late in the semester. Respondents who did not meet a series of decision rules were not included in the study. Only students who completed the surveys were included in the study. Because of the large number of responses, we employed listwise deletion in our analysis, eliminating 148 incomplete responses. This yielded 634 complete responses for the study. These steps were taken to be sure that our sample was representative of the population, the process was standardized, and our data were reliable and did not violate the assumptions of regression analysis. 


\section{Participants}

The study included 634 students (96 freshman, 77 sophomores, 157 juniors, 259 seniors, and 45 graduate students). The mean age for the sample was $23.30(\mathrm{SD}=6.71)$. The sample consisted of 372 males and 262 females who were primarily Caucasian $(81.20 \%, \mathrm{n}=515)$ and had 2.85 years of work experience. Respondents were surveyed from four courses with a total of 52 sections taught by 12 instructors.

\section{Reliability and Validity}

We undertook several procedures to ensure the reliability and validity of our research. We assessed the internal reliability of all used scales employing Cronbach's Index. All Cronbach alpha coefficient renders were acceptable (Nunnally, 1967) and in line with those reported in prior studies.

We evaluated the magnitude of the common method bias employing the post hoc diagnostic Harman single factor test (Harman, 1976; Podsakoff, Mackenzie, Lee, \& Podsakoff, 2003). This test has been the most widely used for this purpose (Podsakoff et al., 2003). Harman's single factor test explains that common method bias is present in the data set when a single factor emerges, or one factor accounts for $>50 \%$ of the variance of the items in the factor analysis. Results of Harman's single-factor test demonstrated the absence of a single factor, and that no factor accounted $>50 \%$ of the variance. We did not observe any unusual variations in the collected responses; no single factor emerged, nor did a single factor account for the majority of the covariance in the measured variables. We further implemented a number of procedural remedies for common method bias (Podsakoff et al., 2003). In particular, all respondents were informed that their answers were anonymous, that there were no right or wrong answers, and that they should complete the questionnaire as honestly as possible. Also, we psychologically separated the measurement of the predictor and criterion variables by interjecting into the questionnaire two measures related to Facebook usage. This way we gave participants the impression that the measurement of the predictor variables was not connected with the measurement of the dependent variables. Overall, we considered common method variance limited and the validity of our measures robust.

\section{Independent Variables}

Perfectionism

Perfectionism was measured using Frost and colleagues' (1990) 6-dimension measure of perfectionism. We used two dimensions for this study as we found them to be theoretically relevant (Concern over Mistakes and Personal Standards). Concern over Mistakes is a 9-item measure with a sample item such as "People will probably think less of me if I make a mistake." The reliability for Concern over Mistakes is sufficient (Cronbach's Alpha, $\alpha=.85$ ). Personal Standards is a 7-item measure and includes items such as "If I do not set the highest standards for myself, I am likely to end up a second-rate person." The reliability for Personal Standards is excellent (Cronbach's Alpha, $\alpha=.85$ ). All items are included in the Appendix.

\section{Ethical Climate}

Ethical climate was measured using Victor and Cullen's (1987) ethical climate scale. While the original scale was composed of 36 items, we modified the scale for this study and used 15 items. Our study focused on four dimensions regarding ethical climate (self-interest, personal morality, rules, and laws/codes). The scale had excellent reliability (Cronbach's Alpha, $\alpha=.82$ ). This scale and its items are also included in the Appendix.

\section{Dependent Variables \\ Impostor Phenomenon}

We measured Impostor Phenomenon with a 20-item scale by Clance (1985). Sample items include "Sometimes I feel or believe that my success in my life or in my job has been the result of some kind of error" and "When people praise me for something I've accomplished, I'm afraid I won't be able to live up to their expectations of me in the future." The reliability estimate for this measure was excellent (Cronbach's Alpha, $\alpha=.92$ ). This scale and all of its items are included in the Appendix. 


\section{Control Variables}

We controlled for sex, race, age, and work experience. Studies have found that sex has a positive and significant relationship with impostor phenomenon, specifically with women (McGregor, Gee, \& Posey, 2008). Clance and Imes (1978) first identified the impostor phenomenon in high achieving women who felt undeserving of their accomplishments.

TABLE 1 DESCRIPTIVES AND CORRELATIONS

\begin{tabular}{|l|c|c|c|c|c|c|c|c|c|c|}
\hline & Mean & $\begin{array}{c}\text { Std. } \\
\text { Deviation }\end{array}$ & 1 & 2 & 3 & 4 & 5 & 6 & 7 & 8 \\
\hline 1. Age & 23.30 & 6.708 & 1 & & & & & & & \\
\hline 2. Sex & 1.41 & 0.493 & 0.069 & 1 & & & & & & \\
\hline 3. Race & 1.43 & 1.146 & $.097^{*}$ & 0.051 & 1 & & & & & \\
\hline $\begin{array}{l}4 . \text { Work } \\
\text { Experience }\end{array}$ & 2.8553 & 6.78428 & $.913^{* *}$ & 0.046 & 0.075 & 1 & & & & \\
\hline $\begin{array}{l}\text { 5. Concern } \\
\text { over } \\
\text { Mistakes }\end{array}$ & 2.7813 & 0.70041 & $-.088^{*}$ & -0.021 & 0.028 & $-.125^{* *}$ & 1 & & & \\
\hline $\begin{array}{l}\text { 6. Personal } \\
\text { Standards }\end{array}$ & 3.6751 & 0.71504 & 0.016 & -0.067 & -0.037 & -0.034 & $.394^{* *}$ & 1 & & \\
\hline $\begin{array}{l}7 . \text { Ethical } \\
\text { Climate }\end{array}$ & 3.2593 & 0.53025 & 0.076 & 0.032 & -0.013 & 0.019 & $.281^{* *}$ & $.321^{* *}$ & 1 & \\
\hline $\begin{array}{l}\text { 8. Impostor } \\
\text { Phenomenon }\end{array}$ & 2.7048 & 0.63870 & -0.025 & $.129^{* *}$ & 0.032 & -0.057 & $.452^{* *}$ & $.134^{* *}$ & $.273^{* *}$ & 1 \\
\hline
\end{tabular}

*. Correlation is significant at the 0.05 level (2-tailed).

**. Correlation is significant at the 0.01 level (2-tailed).

Listwise $\mathrm{N}=634$

\section{Analytic Strategy}

All analyses were conducted using SPSS 24. The analyses were conducted at the individual (i.e., student) level of analysis to accomplish our goal of determining if perfectionism influenced impostor phenomenon and also if ethical climate moderated the perfectionism and impostor phenomenon relationship.

\section{RESULTS}

We used hierarchal linear regressions to test our hypotheses (H1-H4). In Step 1, we entered the control variables (age, race, sex, and work experience) finding that only sex had a significant coefficient ( $\beta=.164$, $\mathrm{p}<.001$ ) (Model 1) when regressed on the impostor phenomenon in both regressions. In the second steps, we entered the independent variables (Concern over Mistakes or Personal Standards), in the third step the moderator (ethical climate), and in the fourth and final step, all the variables were entered, including interaction terms. 
TABLE 2

REGRESSION ANALYSIS - CONCERN OVER MISTAKES ON IMPOSTER PHENOMENON

\begin{tabular}{|c|c|c|c|c|}
\hline & Model 1 & Model 2 & Model 3 & Model 4 \\
\hline Intercept & $2.2 * * *$ & $1.168 * * *$ & $.776 * * *$ & -0.025 \\
\hline \multicolumn{5}{|l|}{ Control Variables } \\
\hline Age & 0.013 & 0.006 & 0.002 & -0.003 \\
\hline Race & 0.015 & 0.006 & 0.009 & 0.012 \\
\hline Sex & $0.164 * * *$ & $.177 * * *$ & $.171 * * *$ & $.174 * * *$ \\
\hline Work Experience & -0.018 & -0.007 & -0.003 & 0.001 \\
\hline \multicolumn{5}{|l|}{ Independent Variables } \\
\hline Concern over Mistakes & & $.412 * * *$ & $.373 * * *$ & $.714 * * *$ \\
\hline \multicolumn{5}{|l|}{ Moderator } \\
\hline Ethical Climate & & & $.185^{* * *}$ & $.455^{* * *}$ \\
\hline \multicolumn{5}{|l|}{ Interaction } \\
\hline Concern over Mistakes x Ethical Climate & & & & $-.101 *$ \\
\hline $\mathbf{N}$ & 634 & 634 & 634 & 634 \\
\hline $\mathbf{R}^{2}$ & 0.025 & 0.225 & 0.246 & 0.251 \\
\hline$\Delta \mathrm{R}^{2}$ & & 0.2 & 0.021 & 0.005 \\
\hline Adjusted $\mathbf{R}^{2}$ & 0.018 & 0.218 & 0.239 & 0.243 \\
\hline $\mathbf{F}$ & 3.953 & 162.032 & 17.587 & 4.537 \\
\hline
\end{tabular}

Using hierarchical regression analysis, we evaluated the hypothesized influence of Ethical Climate on the associations between Concern over Mistakes and Imposter Phenomenon and between Personal Standards and Imposter Phenomenon. In the first hierarchical model (Model 2), Concern over Mistakes was positively related to Imposter Phenomenon, $\beta=.412, \mathrm{p}<.001$, supporting Hypothesis 1 . Ethical Climate was also related to Imposter Phenomenon after controlling for Concern over Mistakes, $\beta=.185, p<.001$ (Model 4). However, evidence suggests that these additive effects are qualified by a statistically significant moderator effect, $\Delta \mathrm{R} 2=.005, \Delta \mathrm{F}=4.537, \mathrm{p}=.034, \beta=-.101, \mathrm{p}=.034$, meaning the effect of Concern over Mistakes on Imposter Phenomenon changes across levels of Ethical Climate, supporting Hypothesis 3 (Model 4). Plotting the regressions revealed that there is a two-way interaction effect between high and low levels of Ethical Climate. 
FIGURE 2

INTERACTION PLOT FOR CONCERN OVER MISTAKES AND ETHICAL CLIMATE ON IMPOSTER PHENOMENON

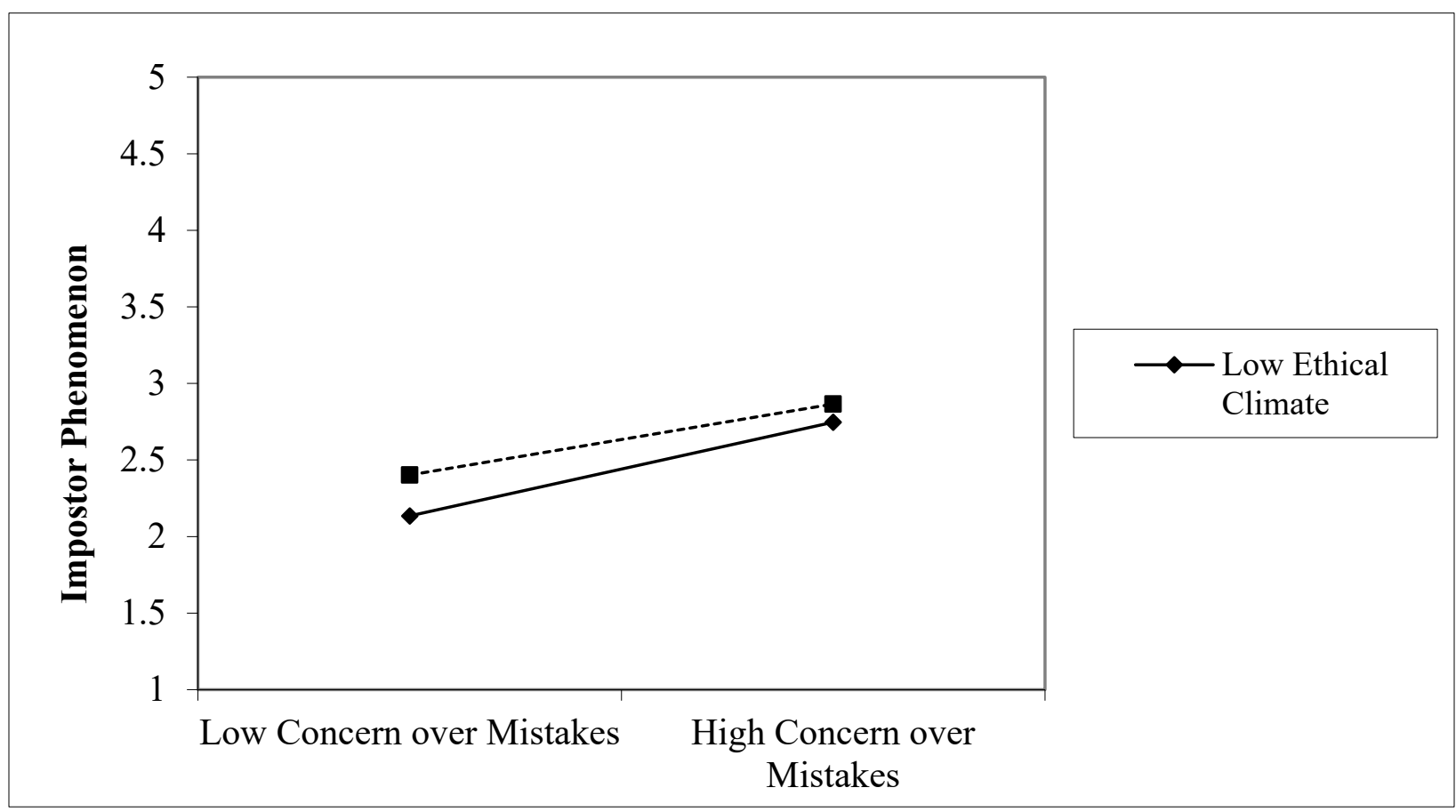

TABLE 3

REGRESSION ANALYSIS - PERSONAL STANDARDS ON IMPOSTER PHENOMENON

\begin{tabular}{|c|c|c|c|c|}
\hline & Model 5 & Model 6 & Model 7 & Model 8 \\
\hline Intercept & $2.2^{* * *}$ & $1.805^{* * *}$ & $0.123^{* * *}$ & 0.17 \\
\hline Control Variables & & & & \\
\hline Age & & & & \\
\hline Race & 0.013 & 0.009 & 0.003 & -0.003 \\
\hline Sex & 0.015 & 0.018 & 0.02 & 0.021 \\
\hline Work Experience & $0.164^{* * *}$ & $0.177^{* * *}$ & $0.162^{* * *}$ & $0.164^{* * *}$ \\
\hline Independent Variables & -0.018 & -0.014 & -0.009 & -0.003 \\
\hline Personal Standards & & & & \\
\hline & & & & $0.377^{* * *}$ \\
\hline Moderator & & $0.123^{* * *}$ & 0.053 & \\
\hline Ethical Climate & & & & \\
\hline Interaction & & & $0.301^{* * *}$ & $0.681^{* * *}$ \\
\hline Personal Standards x Ethical Climate & & & & \\
\hline & & & & $-0.104^{*}$ \\
\hline
\end{tabular}




\begin{tabular}{|r|c|c|c|c|}
\hline $\mathbf{N}$ & 634 & 634 & 634 & 634 \\
\hline $\mathbf{R}^{\mathbf{2}}$ & 0.025 & 0.043 & 0.098 & 0.106 \\
\hline $\boldsymbol{\Delta} \mathbf{R}^{\mathbf{2}}$ & & 0.019 & 0.055 & 0.008 \\
\hline Adjusted $\mathbf{R}^{\mathbf{2}}$ & 0.018 & 0.035 & 0.09 & 0.096 \\
\hline $\mathbf{F}$ & 3.953 & 12.201 & 38.336 & 5.502 \\
\hline
\end{tabular}

In the second hierarchical model, Personal Standards was positively related to Imposter Phenomenon, $\beta=.123, \mathrm{p}<.001$ (Model 6), supporting Hypothesis 2. Ethical Climate was also related to Imposter Phenomenon after controlling for Personal Standards, $\beta=.301, p<.001$ (Model 7). However, evidence suggests that these additive effects are qualified by a statistically significant moderator effect, $\Delta \mathrm{R} 2=.008$, $\Delta \mathrm{F}=5.502, \mathrm{p}=.019, \beta=-.104, \mathrm{p}=.019$, meaning the effect of Personal Standards on Imposter Phenomenon changes across levels of Ethical Climate, supporting Hypothesis 4 (Model 8). Plotting the regressions revealed that there is a two-way interaction effect between high and low levels of Ethical Climate.

FIGURE 3

\section{INTERACTION PLOT FOR PERSONAL STANDARDS AND ETHICAL CLIMATE ON} IMPOSTER PHENOMENON

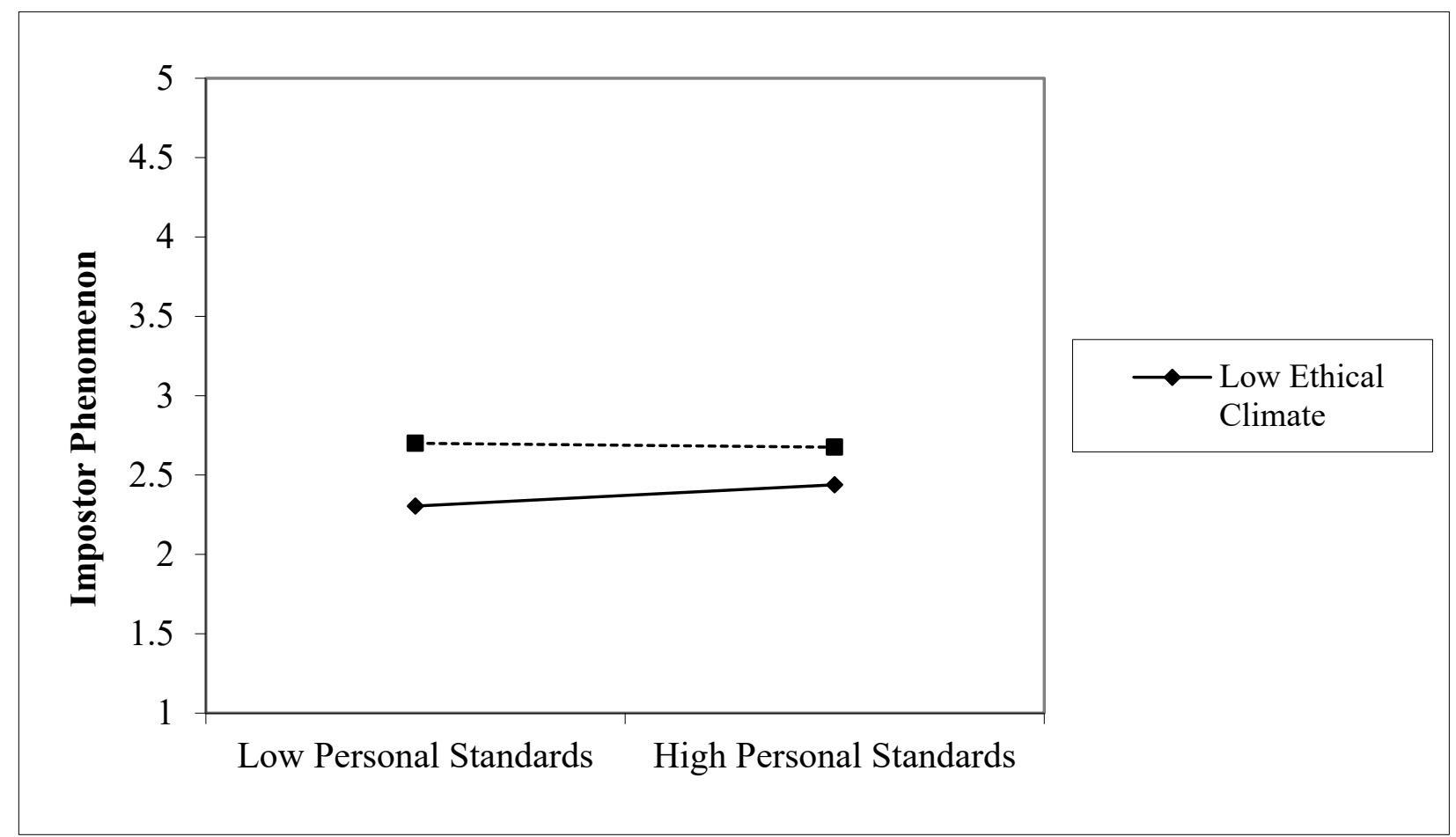

\section{DISCUSSION}

Consistent with previous literature, our results indicate that perfectionism is strongly linked to the impostor phenomenon. We find support for both the maladaptive and adaptive forms of perfectionism. Our findings are not only consistent with extant studies, but plausible given the tendencies of individuals who exhibit perfectionism. Those who are on the maladaptive spectrum (concern over mistakes) are likely to let their concerns over mistakes influence how they think others perceive them as well as how they perceive themselves. On the other hand, individuals exhibiting adaptive perfectionism (personal standards) are simply attempting to achieve their best, but not prone to dysfunction if their goals are not met. 
Consequently, they are content with their achievements and are able to internalize success unlike those who suffer from the impostor phenomenon.

Our study also introduced ethical climate to the perfectionism and impostor phenomenon relationship. We hypothesized that ethical climate is likely to influence this relationship because individuals give weight to the climate that they are in and are likely to develop a sense of ethical concerns and standards based on the climate. Although it was not part of our hypotheses, we found evidence that ethical climate also had a significant and positive relationship with the impostor phenomenon.

\section{Limitations and Future Research}

Our study examines relationships between variables that are self-reported at a single time. While a limitation, our research design also offers a future research agenda. Scholars examining how perfectionism influences the impostor phenomenon and other less desirable traits should design studies that are not only longitudinal, but qualitative. Longitudinal designs would allow scholars to examine how these personality traits and outcomes change over time (e.g., from freshman to senior year to the workplace). We argue that scholars should employ qualitive designs because it might offer lesser known themes associated with perfectionism or the impostor phenomenon.

Second, while we chose ethics as our climate of choice, we could have as easily chosen another climate. Scholars should examine other climates to see their effects on personality and impostor phenomenon relationships. For example, a highly successful climate is also likely to influence perfectionism in a different way than an ethical climate.

Another potential limitation of our study is that common method variance (CMV) may have influenced our results, as most data were collected from a single source. However, the observed interactions argue against such influence, as interactions are robust against CMV (Evans, 1985). Also, results of Harman's single-factor test, and descriptive statistics revealed that common-method bias was not pervasive. While we found that ethical climate has a positive and significant relationship to imposter phenomenon, it is critical at this time that colleges of business and universities to have highly ethical climates. The increases in technological use in the university setting has increased instances of cheating and academic integrity violations (Bain, 2015; O'Neil, 2003). In some instances, students may see cheating as easier than studying or completing the work themselves (Ashworth, P., Bannister, P., Thorne, P., \& Students on the Qualitative Research Methods Course Unit, 1997). Without a high ethical climate, students will not necessarily understand what constitutes as cheating (Ashworth et al., 1997) and thus, perhaps unknowingly, engage in unethical behavior. This not only undermines instructors but entire degrees. It is important across all fields, not just academia, to ensure that students actually learn and can apply high level concepts in practice and one way to accomplish this is through a high ethical climate. A balance between a highly ethical climate and increasing instances of imposter phenomena is critical in the university setting to help keep cheating at a minimum and to keep imposter behaviors in students at a minimum. Future researchers should examine this balance.

\section{Practical Implications}

Our paper offers several practical implications. First, colleges of businesses are influencing the personalities of their business students. Specifically, the climate, ethical or unethical, is influencing behaviors, such as impostor behaviors in students who are about to enter the workplace. Thus, some of the impostor phenomena observed in the workplace actually begins in university studies. Second, university students are increasingly becoming perfectionists without realizing the harmful consequences. These consequences are not only negative in the university setting, but likely later in life in the workplace. However, perfectionism, in both maladaptive and adaptive forms, is usually offered as a "weakness" in interview settings. Our study suggests that the practical implications of perfectionism, on average, can have longer lasting negative consequences than imagined. Organizations gloss over the idea that they are recruiting or interviewing "perfectionists," but organizations are less likely to be enthusiastic about hiring an impostor. 


\section{CONCLUSION}

Our study explored the associations between Concern of Mistakes, Personal Standards, and Ethical Climate on Imposter Syndrome. We found support that perfectionism and imposter syndrome are positively associated in student populations. Again, the maladaptive form of perfectionism, concern over mistakes may need to be addressed more formally to ensure that students are not developing habits that may exacerbate future impostor feelings. Emphasis may be directed at encouraging students to recognize that although positive outcomes are preferred, they are in a learning environment and there must be a less negative stigma attached to mistakes and poor outcomes in general during this learning process. These are the proving grounds where knowledge is gained and expanded but it is not without occasional failure. Perhaps additional focus on student's overall improvements, and less emphasis on mistakes will encourage the self-perceived impostors to take respite from their feelings of imposterism and place more weight on the bigger picture of their overall progress. Just as we do not want to stifle growth and creativity in the workplace by focusing on periodic failure, we should highlight the benefits of what has been learned in the academic setting so it can be applied more positively to the future.

\section{REFERENCES}

Ashworth, P., Bannister, P., Thorne, P., \& Students on the Qualitative Research Methods Course Unit. (1997). Guilty in whose eyes? University students' perceptions of cheating and plagiarism in academic work and assessment. Studies in Higher Education, 22(2), 187-203.

Bain, L.Z. (2015). How students use technology to cheat and what faculty can do about it. Information Systems Education Journal, 13(5), 92-99.

Blatt, S.J. (2004). Experiences of depression: Theoretical, clinical, and research perspectives. Washington, DC: American Psychological Association.

Bieling, P.J., Israeli, A.L., \& Antony, M.M. (2004). Is perfectionism good, bad, or both? Examining models of the perfectionism construct. Personality and Individual Differences, 36(6), 1373-1385.

Bernard, N.S., Dollinger, S.J., \& Ramaniah, N.V. (2002). Applying the big five personality factors to the impostor phenomenon. Journal of Personality Assessment, 78(2), 321-333.

Brown, M.E., Treviño, L.K., \& Harrison, D.A. (2005). Ethical leadership: A social learning perspective for construct development and testing. Organizational Behavior and Human Decision Processes, 97, 117-134.

Bussotti, C. (1990). The impostor phenomenon: Family roles and environment. (Doctoral dissertation, Georgia State University). Dissertation Abstracts International, 51, 4041B-4042B.

Caselman, T.D. (2003). The imposter phenomenon among American and Japanese adolescents: Gender, self-perception, self-concept and social support variables. Dissertation Abstracts International: Section B: The Sciences and Engineering, 64(6-B), 2955.

Chae, J.H., Piedmont, R.L., Estadt, B.K., \& Wicks, R.J. (1995). Personological evaluation of Clance's Impostor Phenomenon Scale in a Korean sample. Journal of Personality Assessment, 65(3), 468485.

Chrisman, S., Pieper, W., Clance, P., Holland, C., \& Glickauf-Hughes, C. (1995). Validation of the Clance impostor phenomenon Scale. Journal of Personality Assessment, 65, 456-467.

Clance, P.R. (1985). The Impostor Phenomenon: Overcoming the Fear that Haunts Your Success. Atlanta, GA: Peachtree.

Clance, P., \& Imes, S. (1978). The impostor phenomenon in high achieving women: Dynamics and therapeutic intervention. Psychotherapy: Theory, Research, and Practice, 15, 241-247.

Crawford, W., Shanine, K., Whitman, M., \& Kacmar, K. (2015). Examining the impostor phenomenon and work-family conflict. Journal of Managerial Psychology, 31(2), 375-390.

Cromwell, B., Brown, N., Sanchez-Huceles, J., \& Adair, E.L. (1990). The impostor phenomenon and personality characteristics of high school honor students. Journal of Social Behavior and Personality, 5(6), 563-573. 
Cusack, C.E., Hughes, J.L., \& Nuhu, N. (2013). Connecting gender and mental health to imposter phenomenon feelings. Psi Chi Journal of Psychological Research, 18(2), 74-81.

Deshpande, S.P., George, E., \& Joseph, J. (2000). Ethical climates and managerial success in Russian organizations. Journal of Business Ethics, 23(2), 211-217.

Dudau, D.P. (2014). The relation between perfectionism and impostor phenomenon. Procedia-Social and Behavioral Sciences, 127, 129-133.

Evans, M.G. (1985). A Monte Carlo study of the effects of correlated method variance in moderated multiple regression analysis. Organizational Behavior and Human Decision Processes, 36, 305 323.

Ferrari, J.R., \& Thompson, T. (2006). Impostor fears: Links with self-presentational concerns and selfhandicapping behaviours. Personality and Individual Differences, 40(2), 341-352.

Flett, G.L., Hewitt, P.L., Oliver, J.M., \& Macdonald, S. (2002). Perfectionism in children and their parents: A developmental analysis. In G.L. Flett \& P.L. Hewitt (Eds.), Perfectionism: Theory, research, and treatment (pp. 89-132). Washington, DC: American Psychological Association.

Fried-Buchalter, S. (1992). Fear of success, fear of failure, and the imposter phenomenon: A factor analytic approach to convergent and discriminant validity. Journal of Personality Assessment, $58(2), 368-379$.

Fritzsche, D.J. (2000). Ethical climate and the ethical dimension of decision making. Journal of Business Ethics, 24, 125-140.

Frost, R.O., Marten, P., Lahart, C., \& Rosenblate, R. (1990). The dimensions of perfectionism. Cognitive Therapy and Research, 14(5), 449-468.

Frost, R.O., Turcotte, T.A., Heimberg, R.G., Mattia, J.I., Holt, C.S., \& Hope, D.A. (1995). Reactions to mistakes among subjects high and low in perfectionistic concern over mistakes. Cognitive Therapy and Research, 19(2), 195-205.

Gibson-Beverly, G., \& Schwartz, J.P. (2008). Attachment, entitlement, and the impostor phenomenon in female graduate students. Journal of College Counseling, 11(2), 119-132.

Grammas, D.L., \& Schwartz, J.P. (2009). Internalization of messages from society and perfectionism as predictors of male body image. Body Image, 6(1), 31-36.

Gravois, J. (2007). You're not fooling anyone. The Chronicle of Higher Education, 54(11), A1. Retrieved November 5, 2008, from http://chronicle.com

Harman, H.H. (1976). Modern factor analysis. University of Chicago Press.

Henning, K., Ey, S., \& Shaw, D. (1998). Perfectionism, the impostor phenomenon and psychological adjustment in medical, dental, nursing and pharmacy students. Medical Education, 32, 456-464.

Hewitt, P.L., \& Flett, G.L. (2002). Perfectionism and stress processes in psychopathology. In G.L. Flett \& P.L. Hewitt (Eds.), Perfectionism: Theory, research, and treatment (pp. 255-284). Washington, DC: American Psychological Association.

Hollender, M.H. (1965). Perfectionism. Comprehensive Psychiatry, 6(2), 94-103.

Hutchins, H.M., \& Rainbolt, H. (2017). What triggers imposter phenomenon among academic faculty? A critical incident study exploring antecedents, coping, and development opportunities. Human Resource Development International, 20(3), 194-214.

Imes, S.A., \& Clance, P.R. (1984). Treatment of the Impostor Phenomenon in High Achieving Women. In C. Brody (Ed.), Women Working With Women (pp. 75-88). NY: Snapfinger Publishing Co.

Kelley, S.W. (1992). Developing customer orientation among service employees. Journal of the Academy of Marketing Science, 20(1), 27-36.

Kets de Vries, M.F.K. (2005). The dangers of feeling like a fake. Harvard Business Review, 83, 108-116.

Komaki, J. (2003). Reinforcement theory at work: Enhancing and explaining what employees do. In L.W. Porter, G.A. Bigley, \& R.M. Steers (Eds.), Motivation and work behavior (7th ed., pp. 95-113).

Burr Ridge, IL: Irwin/McGraw-Hill.

Langford, J. (1990). The need to look smart: The impostor phenomenon and motivations for learning (Doctoral dissertation, Georgia State University-College of Arts and Sciences). 
LaSota, M.T., \& Kearney, C.A. (2017). Maladaptive perfectionism and depression and state-trait anxiety: A mediational analysis with self-esteem. Journal of Social and Clinical Psychology, 36(4), 346357.

Luria, G., \& Yagil, D. (2008). Procedural justice, ethical climate and service outcomes in restaurants. International Journal of Hospitality Management, 27(2), 276-283.

Mattie, C., Gietzen, J., Davis, S., \& Prata, J.W. (2008). The imposter phenomenon: Self-Assessment and competency to perform as a physician assistant in the United States. The Journal of Physician Assistant Education, 19(1), 5-12.

Mayer, D.M., Kuenzi, M., \& Greenbaum, R.L. (2010). Examining the link between ethical leadership and employee misconduct: The mediating role of ethical climate. Journal of Business Ethics, 95(1), 7-16.

Mayer, D.M., Kuenzi, M., Greenbaum, R., Bardes, M., \& Salvador, R.B. (2009). How low does ethical leadership flow? Test of a trickle-down model. Organizational Behavior and Human Decision Processes, 108(1), 1-13.

McDowell, W.C., Grubb, W.L., III, \& Geho, P.R. (2015). The Impact of Self-Efficacy and Perceived Organizational Support on the Impostor Phenomenon. American Journal of Management, 15, 23 29.

McElwee, R.O., \& Yurak, T.J. (2007). Feeling versus acting like an impostor: Real feelings of fraudulence or self-presentation? Individual Differences Research, 5(3), 201-220.

McGregor, L.N., Gee, D.N., \& Posey, K.E. (2008). I feel like a fraud and it depresses me: The relation between the imposter phenomenon and depression. Social Behavior and Personality, 36, 43-48.

Nunnally, J.C. (1967). Psychometric theory (1st ed.). New York: McGraw-Hill.

O’Neil, T.D. (2003). Technology and Academic Integrity, Cheating Goes Cyber. Information Systems Education Journal, 1(3), 3-9.

Perloff, R.M. (2014). Social media effects on young women's body image concerns: Theoretical perspectives and an agenda for research. Sex Roles, 71(11), 363-377.

Podsakoff, P.M., MacKenzie, S.B., Lee, J.Y., \& Podsakoff, N.P. (2003). Common method biases in behavioral research: A critical review of the literature and recommended remedies. Journal of Applied Psychology, 88(5), 879-903.

Rosen, L.D., Whaling, K., Rab, S., Carrier, L.M., \& Cheever, N.A. (2013). Is Facebook creating "iDisorders"? The link between clinical symptoms of psychiatric disorders and technology use, attitudes and anxiety. Computers in Human Behavior, 29(3), 1243-1254.

Ross, S.R., Stewart, J., Mugge, M., \& Fultz, B. (2001). The impostor phenomenon, achievement dispositions, and the five-factor model. Personality and Individual Differences, 31(8), 1347 1355.

Sakulku, J., \& Alexander, J. (2011). The impostor phenomenon. International Journal of Behavioral Science, 6(1), 75-97.

Salancik, G.R., \& Pfeffer, J. (1978). A social information processing approach to job attitudes and task design. Administrative Science Quarterly, pp. 224-253.

September, A.A., McCarrey, M., Baronowsky, A., Parent, C., \& Schindler, D. (2001). The relationship between well-being, imposter feelings, and gender role orientation among Canadian university students. The Journal of Social Psychology, 141(2), 218-232.

Shafran, R., \& Mansell, W. (2001). Perfectionism and psychopathology: A review of research and treatment. Clinical Psychology Review, 21(6), 879-906.

Skinner, B.F. (1969). Contingencies of reinforcement. New York: Appleton-Century-Crofts.

Smith, M.M., Saklofske, D.H., Yan, G., \& Sherry, S.B. (2017). Does perfectionism predict depression, anxiety, stress, and life satisfaction after controlling for neuroticism? Journal of Individual Differences, 38(2), 63-70.

Sonnak, C., \& Towell, T. (2001). The impostor phenomenon in British university students: Relationships between self-esteem, mental health, parental rearing style and socioeconomic status. Personality and Individual Differences, 31(6), 863-874. 
Stoeber, J., \& Otto, K. (2006). Positive conceptions of perfectionism: Approaches, evidence, challenges. Personality and Social Psychology Review, 10(4), 295-319.

Tett, R.P., \& Burnett, D. (2003). A personality trait-based interactionist model of job-performance. Journal of Applied Psychology, 88, 500-517.

Thompson, T., Davis, H., \& Davidson, J. (1998). Attributional and affective responses of impostors to academic success and failure outcomes. Personality and Individual Differences, 25(2), 381-396.

Thompson, T., Foreman, P., \& Martin, F. (2000). Impostor fears and perfectionistic concern over mistakes. Personality and Individual differences, 29(4), 629-647.

Topping, M.E.H. (1983). The Impostor Phenomenon: A study of its construct and incidence in university faculty members. (Doctoral Dissertation, University of South Florida, 1983). Dissertation Abstracts International, 41, 4248A-4249A.

Topping, M.E.H., \& Kimmel, E.B. (1985). The impostor phenomenon: Feeling phone. Academic Psychology Bulletin, 7(2), 213-226.

Treviño, L.K., Butterfield, K.D., \& McCabe, D.L. (1998). The ethical context in organizations: Influences on employee attitudes and behaviors. Business Ethics Quarterly, 8(3), 447-476.

Treviño, L.K., Weaver, G.R., \& Reynolds, S.J. (2006). Behavioral ethics in organizations: A review. Journal of Management, 32(6), 951-990.

Vardi, Y. (2001). The effects of organizational and ethical climates on misconduct at work. Journal of Business Ethics, 29(4), 325-337.

Victor, B., \& Cullen, J.B. (1987). A theory and measure of ethical climate in organizations. Research in Corporate Social Performance and Policy, 9(1), 51-71.

Victor, B., \& Cullen, J.B. (1988). The organizational bases of ethical work climates. Administrative Science Quarterly, pp. 101-125.

Zohar, D., \& Luria, G. (2004). Climate as a social-cognitive construction of supervisory safety practices: Scripts as proxy of behavior patterns. Journal of Applied Psychology, 89(2), 322-33.

\section{APPENDIX}

\section{Survey Measures}

Impostor Phenomenon

For each question, please circle the number that best indicates how true the statement is of you. It is best to give the first response that enters your mind rather than dwelling on each statement and thinking about it over and over.

Items are scored 1 (not at all true), 2 (rarely), 3 (sometimes), 4 (often), 5 (very true)

1. I have often succeeded on a test or task even though I was afraid that I would not do well before I undertook the task.

2. I can give the impression that I'm more competent than I really am.

3. I avoid evaluations if possible and have a dread of others evaluating me.

4. When people praise me for something I've accomplished, I'm afraid I won't be able to live up to their expectations of me in the future.

5. I sometimes think I obtained my present position or gained my present success because I happened to be in the right place at the right time or knew the right people.

6. I'm afraid people important to me may find out that I'm not as capable as they think I am.

7. I tend to remember the incidents in which I have not done my best more than those times I have done my best.

8. I rarely do a project or task as well as I'd like to do it.

9. Sometimes I feel or believe that my success in my life or in my job has been the result of some kind of terror.

10. It's hard for me to accept compliments or praise about my intelligence or accomplishments.

11. At times, I feel my success has been due to some kind of luck. 
12. I'm disappointed at times in my present accomplishments and think I should have accomplished much more.

13. Sometimes I'm afraid others will discover how much knowledge or ability I really lack.

14. I'm often afraid that I may fail at a new assignment or undertaking even though I generally do well at what I attempt.

15. When I've succeeded at something and received recognition for my accomplishments, I have doubts that I can keep repeating that success.

16. If I receive a great deal of praise and recognition for something I've accomplished, I tend to discount the importance of what I've done.

17. I often compare my ability to those around me and think they may be more intelligent than I am.

18. I often worry about not succeeding with a project or examination, even though others around me have considerable confidence that I will do well.

19. If I'm going to receive a promotion or gain recognition of some kind, I hesitate to tell others until it is an accomplished fact.

20. I feel bad and discouraged if I'm not "the best" or at least "very special" in situations that involve achievement.

Concern Over Mistakes (CM)

1. If I fail at work/ school, I am a failure as a person.

2. I should be upset if I make a mistake.

3. If someone does a task at work/ school better than I, then I feel like I failed the whole task.

4. If I fail partly, it is as bad as being a complete failure.

5. I hate being less than the best at things.

6. People will probably think less of me if I make a mistake.

7. If I do not do as well as other people, it means I am an inferior human being.

8. If I do not do well all the time, people will not respect me.

9. The fewer mistakes I make, the more people will like me.

Personal Standards (PS)

1. If I do not set the highest standards for myself, I am likely to end up a second-rate person.

2. It is important to me that I be thoroughly competent in everything I do.

3. I set higher goals than most people.

4. I am very good at focusing my efforts on attaining a goal.

5. I have extremely high goals.

6. Other people seem to accept lower standards from themselves than I do.

7. I expect higher performance in my daily tasks than most people.

\section{Ethical Climate}

1. In the College of Business, people are mostly out for themselves.

2. There is no room for one's own personal morals or ethics here.

3. In the $\mathrm{COB}, \mathrm{Students}$ protect their own interest above other considerations.

4. Students in the COB are very concerned about what is best for themselves.

5. In the College of Business, people are expected to follow their own personal and moral beliefs.

6. Each student here in the COB decides for himself what is right and wrong.

7. The most important consideration in the COB is each student's sense of right and wrong.

8. In the $\mathrm{COB}$, students are guided by theft own personal ethics.

9. It is very important to follow strictly the rules and procedures here.

10. Students are expected to follow the COB's rules and procedures.

11. Successful students follow the rules.

12. Successful students in the COB strictly obey the college policies. 
13. Students are expected to comply with the rules and professional standards over and above other considerations.

14. In the $\mathrm{COB}$, students are expected to strictly follow legal or professional standards.

15. In the $\mathrm{COB}$, the ethical code in the student handbook is a major consideration. 